\title{
Split Brains: No Headache for the Soul Theorist
}

\author{
DAVID B. HERSHENOV \\ Department of Philosophy, University at Buffalo, Buffalo NY,14217 USA dh25@buffalo.edu
}

ADAM P. TAYLOR

Department of History, Philosophy and Religious Studies, North Dakota State University, Fargo, ND, 58108-6050, USA aptaylor@gmail.com

\begin{abstract}
Split brains that result in two simultaneous streams of consciousness cut off from each other are wrongly held to be grounds for doubting the existence of the divinely created soul. The mistake is based on two related errors: first, a failure to appreciate the soul's dependence upon neurological functioning. Secondly, a fallacious belief that if the soul is simple, i.e., without parts, then there must be a unity to its thought, all of its thoughts potentially accessible to reflection or even unreflective causal interactions. But a soul theorist can allow neurological events to keep some conscious thoughts unavailable to others.
\end{abstract}

\section{Introduction}

It is commonly thought that the phenomenon of the split brain delivers a decisive knockout blow to soul theories. ${ }^{1}$ The phenomenon is well known to neuroscientists as well as philosophers of mind. Brain splitting involves a surgical procedure known as commissurotomy, which severs the neural fibers of the corpus callosum, resulting in either a partial or complete interruption of interhemispheric communication. As a consequence of the procedure, which was first developed as a means to treat epileptic seizures, the patients experience a bifurcation of consciousness into two apparent "streams-of-thought." Materialist philosophers of mind have widely contended that these results contradict the supposed unity and simplicity of the soul. This will be unwelcome news to the many theists who believe their religious beliefs require they be immaterial or have an immaterial component. $^{2}$

But to continue with the boxing metaphor that began this paper, we don't think split brains even help the materialist contenders win their bouts with dualists on points. The fact that the splitting of the brain results in two contemporaneous spheres of consciousness that are in some 
ways inaccessible to the other is not grounds for denying that there is one soul involved, the same soul that was thinking the person's thoughts before the brain splitting. The mistake is based on two related errors. First, such a position fails to appreciate the soul's dependence upon neurological functioning. Secondly, such a mistake is grounded in a fallacious belief that if the soul is simple, i.e., without parts, then there must be a unity to its thought. Thus unity could consist in all of its thoughts potentially accessible to (self-conscious) reflection or, at least, unreflective (merely conscious) causal interactions. But a soul theorist can allow neurological events to keep some conscious thoughts unavailable to others.

Our contention is that not only should theists realize that split brains aren't a problem for their soul theories, but an extension of the phenomenon actually provides support for a divine creation account of the soul over the rival accounts of emergent dualists or Unger's dispositional theory of the soul. As pointed out long ago by Parfit, if the two separated cerebral hemispheres can each give rise to conscious states then, barring technical problems, it should be possible to transplant each consciousness-supporting hemisphere into a different brain (Parfit (1984), 251-55). Assuming the two resulting thinking beings would be distinct agents and persons, then there will be a need for at least one new soul attached to one of the cerebral hemispheres. However, an account needs to be given why two more souls didn't emerge or were disposed to interact with the separated cerebral hemispheres before the fission and transplant. The emergent dualist and the dispositional soul theorist need the hemispheres to somehow prevent the appearance of another soul prior to the fissioning and transplant without preventing the presence of the single soul correlated with the entire brain. The theist has the advantage of a less convoluted theory in which God bestows just one soul upon the typical person's body and then bestows the souls needed in the fission and transplant scenario to ensure that there are two agents controlling their respective bodies. ${ }^{3}$ 


\section{The Split Brain Objection to Dualism}

Jeff McMahan offers what we take to be a standard form of these objections to the soul based on the split brain phenomenon. He believes that souls are individuated, at least in part, by the range of thoughts that are consciously grasped. Any thoughts that an immaterial subject can't access won't belong to that particular soul. As he says:

"If the soul is understood as the subject of consciousness, its boundaries are determined by what it is conscious of. All conscious events occurring simultaneously in a single soul must be co-conscious. If, for example, my soul is the substance coextensive with this field of consciousness, then any conscious events that are occurring now that are not within this field - any conscious events of which I am not now conscious - must be events within a different field of consciousness, a different soul. ... a single soul cannot have a divided consciousness” (McMahan (2002), 21).

We don't see why the conclusion follows that a soul can't have a divided consciousness even if we grant that the soul is conscious of all of its thoughts and some mental events are simultaneously thought. The fact that a single entity can have two streams of consciousness is not at odds with the claim that the same entity is conscious of both. It is just that they don't interact in a single stream of thought. Even insisting that a soul is self-conscious doesn't rule out a split brain for the same soul could be self-conscious of both streams but doesn't entertain contents of both in the same reflections. Perhaps the guiding assumption is an understanding of "co-conscious" that renders consciousness or self consciousness of simultaneous thoughts to mean that they can be thought in relation to each other. This would involve each thought related to another in that each can influence the other or be compared with the other. It seems that it is only that understanding of necessary co-consciousness that rules out the soul having a divided consciousness. 
Why maintain that each thought of one and the same soul should be (potentially) involved with every other thought of that soul? Well, it might be because the soul is not extended with parts that can be physically cut off from each other thus blocking communication. This guiding assumption is still spatial in that it treats the soul as if it is either point-like and all of its thoughts are in the same place, or the soul is an extended simple, spread out but without parts able to block access of one conscious state to another. Since they are all together at the same partless location, they must be involved with each other. Notice the spatial language of being co-extensive with a field in McMahan's earlier quote. It seems that McMahan pictures the soul as being (at least somewhat) analogous to a spatial region. Such regions have clear boundaries, and for any such region, $R_{1}$, all events occurring within $R_{1}$ must be co-located within $R_{1}$. Any events that are not co-located within $R_{1}$, must be happening in another region, $R_{n}$.

In a split brain scenario, certain streams of thought occur in ignorance of each other. A materialist conception of a thinking organism or brain with its spatial parts can easily make sense of thoughts cut off from each other. They are just realized in different parts of the brain, the connections between such segments severed. But a soul doesn't have spatial divides, so all of its contents should be available to such an immaterial thinker.

It would then seem that a split brain must involve a creation of a new soul or two. And since souls are simple, the original soul can’t split into two. So either the original soul goes out of existence or remains as one of the two resulting souls. But then when the corpus callosum is restored and unity regained, either we have a new soul which mysteriously has the contents of the predecessors or one of the two souls disappeared and its contents miraculously transferred to the other.

Parfit sees the split brain phenomena as reasons to deny what he calls non-reductionist account of the person, the paradigm example being the Cartesian soul. The person is not something 
over and above the brain, body and its thoughts. Parfit introduces a thought experiment involving two hemispheres that are each equally able to support the person's full psychological profile, and a subject who has been equipped with a means of deliberately blocking the communication between hemispheres. When the subject is faced with a difficult physics problem, she decides to activate the device and pursue separate possible solutions to the problem with each hand, the right hand will work on one possible solution, the left on another. When the solutions have been reached, the hemispheres will be reunited and the subject will be able to recall both streams of consciousness. Parfit argues that it is mistaken to object that this picture ignores the necessity of the unity of consciousness. This is because Parfit denies any such necessity. He argues that consciousness is more like a river than a canal. It can divide and reunite as a river does while flowing around an obstacle. When the mind of the subject in the physics exam case divides, two separate consciousnesses are produced. Each consciousness is itself unified, and each is distinct from the other. And neither is the person. Parfit thinks for reasons such as these we do better to adopt a reductionist account of persons which redescribes facts about persons in which the world could be given an entirely impersonal description. He claims:

Because we ascribe thoughts to thinkers, it is true that thinkers exist. But thinkers are not separately existing entities. The existence of a thinker just involves the existence of his brain and body, the doing of his deeds, and the occurrence of certain other physical and mental events. We could therefore describe any person's life in impersonal terms. In explaining the unity of the life, we need not claim this is the life of a particular person...these claims are supported by the case where I divide my mind. It is not merely true here that the unity of different experiences does not need to be explained by ascribing all of these experiences to me. The unity of my experiences, in each stream, cannot be explained in this way. There only two 
alternatives. We might ascribe the experiences in each stream to a subject of experiences which is not me, and, therefore, not a person. Or, if we doubt the existence of such entities, we can accept the Reductionist explanation. (Parfit (1984),. 251).

Perhaps lurking in the background of McMahan and Parfit's thought is an understanding like van Inwagen's of the soul as a long distance remote control device interacting with the brain or body (van Inwagen (1993), 179). If neurological structures are damaged or inhibited, that should stop communication but not thought. The soul should be able to think during the period that the body is incapacitated, but it would not be able to communicate those thoughts via the organs of the body. But we think this involves a failure to appreciate the dependence of the soul on the brain. It is not actively engaged in thought when the brain is not providing sensations. It isn't as if it has its own resources which are all self contained, so when the brain is cut off as a source of sensations, the soul can still entertain various thoughts, drawing upon its memories to engage in further reasoning. We don't conceive of the soul as such an active and independent thinker, able without the brain, to reflect on anything that has transpired before.

Let us first point out that emergent dualists such as Hasker (1999) and Zimmerman (2010), as well as those who believe souls are divinely paired up with bodies like Plantinga (2007), or those who accept Unger's (2006) dispositionally paired soul, all posit a dependence of thought on the brain. ${ }^{4}$ Zimmerman goes so far as to say that "All contemporary dualists (among philosophers, at least) admit that the ability to think depends on a properly functioning brain" (Zimmerman (2010), 135). The emergentists argue that consciousness arises whenever the brain reaches a certain threshold level of organizational complexity. In less complex states, matter exhibits no consciousness. But when properly organized in the brain, it gives rise to the conscious soul. Hasker uses the analogy of the field generated by a magnet in order to help us grasp the emergentist's 
position. Magnets generate magnetic fields in virtue of the alignment of the micro-fields of their constituent iron molecules. But the magnet and the field it generates are not identical. This is shown by the fact that the magnetic field occupies a region much larger than the magnet does.

Furthermore, once the field is generated it takes on sui generis causal powers, moving the magnet itself (Hasker (2002), 190). Similarly the brain produces a soul-field which gives rise to causal powers distinct from those of the brain (for instance allowing for libertarian freedom and the unifying of conscious states, both of which Hasker thinks raises difficulties for property dualism ). Zimmerman, also an emergentist, likewise maintains that the soul depends on the brain. He argues that once there is sufficient neural activity to give rise to consciousness, there will be a subject for that consciousness which is also generated (Zimmerman (2010), 146).

Plantinga argues for a different account of the dependence of the soul on the brain. On his view, which presumes theism, souls are paired with brains by divine act. And while he admits that "appropriate brain activity is a necessary condition for mental activity" he resists the urge to identify mental activities with the brain activities they depend on (Plantinga (2007), 135). He points out that many activities (e.g. walking, mountain climbing, and digesting) depend on the proper function of the brain, but this alone does not make them activities of the brain and nothing else. Dependence is not identity. If it were, Plantinga argues, then, since brain activity depends on blood flow and the proper functioning of the lungs, we'd have reason to conclude that brain activities were really cardiopulmonary activities.

A third option for the dualist is Peter Unger's dispositionally paired soul (Unger (2006), 151155) Unger's account of the soul's relation to the person's brain (or brains) begins, quite speculatively, in the "monistic plenum" that preceeded the primordial physical universe. He imagines a "Super Big Bang" which then splits reality into two realms. On the one hand there is the spatial realm which contains the physical universe, and on the other hand there is a non-spatial, but 
spacelike, realm that contains immaterial simples. ${ }^{5}$ The immaterial simples possess the requisite dispositions to pair with sufficiently complex "brainy" matter so as to manifest a singular consciousness. He imagines that these souls would have been waiting around for billions of years for their reciprocating material partners to take shape. Elsewhere Unger claims that all souls (not just human souls, but also animal souls) are equivalently rich in their dispositions to produce thought (in concert with the right matter). So how do we explain the differences in the quality of thoughts these equivalently rich souls in fact produce? He argues that difference between a cat and a human is that the human has a better brain to go along with his richly "propensitied" soul. ${ }^{6}$ As he puts it the human has "got a grand piano" and the cat has "got just a darned kazoo." This dependency upon our brains, also explains, Unger suggests, how damage to the brain effects thought. In order to exercise its rational powers to the fullest, the soul needs a well-functioning brain.

As will be discussed in a moment, we believe that many critics of soul theories, and indeed many soul theorists, have failed to take seriously enough the proposition that thought depends upon the brain. Critics of soul theories, like McMahan and Parfit, fail to take seriously the notion that the thoughts of the soul are determined by the functioning of the brain. They seem to think of the soul as somewhat independent of the brain, rather like an omnipotent homunculus sitting at the controls of the brain and capable of controlling and correlating its states, regardless of what is going on within. And this mistake makes the soul theory seem weaker than it really is with respect to split brain phenomena. On our view, the brain makes a crucial contribution to the production of thought but it is not a thinker. A rough analogy for a materialist is that they believe the full materially person needs his eyes, but the eyes aren't the perceiver. Just as we can't see without our eyes, so is it that we can't think without a brain (or a similarly cognitively functional substitute). As Aristotle and later Thomas observed, the eye is to sight as the body is to the soul. The soul is not empowered so as to actively shuffle about the contents provided by the brain without regard for how those contents are 
organized in the brain, any more than the person is capable of arranging the contents of her vision without regard for how that eyes and brain organize that experience. Rather the soul is more passive or dependent with respect to the brain, receiving its mental contents as they are in situ, and unifying them into the thought life of a single subject. Without the unity and subjectivity provided by the soul, thought couldn't occur, but nor could it occur without the contributions provided to the soul by the properly functioning brain.

Now let's turn to the question of the soul's unity which is allegedly threatened by the split brain case. To soften up the reader to the idea that that the soul's thoughts need not be always accessible to self-conscious reflection or mutually influencing each other, consider first the diachronic case involving memory loss. Surely opponents of soul theories aren't going to deny that the soul can be diachronically cut off from some of its past. We don't think it is different souls that are involved when one can't recall a name or event from one's past experience. Thus it appears that the same soul can have contents at one time that are inaccessible to it at another. So does synchronic inability of some thoughts of the soul to be about other thoughts of that soul give us a distinctive reason to abandon one's belief in the soul? We think the diachronic and the synchronic can be treated alike. Some readers may think the degree of inaccessibility distinguishes the synchronic from the diachronic but we think that consideration will lose its force from what is said later in this paper.

Moreover, a soul need not be self-conscious. If newborns are ensouled and conscious, they are not self-conscious. But the same soul will later actualize such capacities. Why then say the thoughts belong to the same soul and newborn person? One reason is the causal connections between stages of the child's mind. But we think it better to stress the sameness of the brain linking a soul at one time to the same soul at another time. Of course, when the brain is split, there won't be causal connection, at least not the ordinary ones within a normal person. 
Now onto our main defense which unifies the neurological dependence thesis with the inaccessibility to consciousness. The same soul can be thinking both streams of thought of the split brain patient. Parts, which the soul lacks, ${ }^{7}$ are not needed to explain the division of thought, that is, a single subject with a divided mind. The dependency on the spatially dependent brain and its parts is enough.

Souls are paired with brains. As a result they have access to thoughts subserved by that brain, and that access occurs in a manner unlike the manner in which they have access to another person's thoughts. When the brain is split, the soul still thinks all the thoughts realized or subserved somehow by the brain, but those thoughts lack some of their standard interactions. This is a synchronic version of someone being unable to recall something for a period, yet perhaps later being able to. The soul's dependence upon the brain explains why thoughts in the soul can be isolated from each other. The physical realizations in the brain are isolated from each other. The soul will not be entertaining thoughts independently of certain brain activities. One should avoid being misled by the soul's simplicity to mean that all of its thoughts must be involved with each other. Perhaps, as we hinted earlier, such an error still involves something like spatializing the soul as a simple all in one place, perhaps the soul is being conceived as point-like or an extended simple without internal barriers. One then assumes that either the thoughts are "piled up" on each other or flow into each other. But that is a mistake; it is projecting the spatial relations of the brain onto the soul. The soul's having no parts is no reason to claim that all of its thoughts are stored together in some sort of coconscious causal interaction. The simplicity of the soul doesn't mean that it can compare any thoughts it thinks. The soul's comparing thoughts, like its thinking any thoughts, depends upon the brain. If the neurological structures are not properly related, neither will be the thoughts of the soul. The split brain prevents neurological interactions which prevents the soul not from thinking the 
thoughts dependent upon different hemispheres, but from thinking those thoughts together in a way that they can interact and produce further thoughts that depend upon that mutual influence.

The soul can only think certain thoughts that have a neurological basis. Destroy that basis and the soul cannot entertain thoughts. And here is the key notion of our thesis: connections between thoughts require connections between various parts of the brain. The mistake exemplified by McMahan is to think since the soul is simple, then it can reflect at any time on any of the contents in its "field of consciousness." We contend that McMahan and others mistakenly picture the soul as having either a spatial, perhaps point-like location, or an extended simple without internal barriers. We call this the global workspace account of the soul. ${ }^{8}$ According to this view, the soul acts as a sort of immaterial (though somehow spatial) blackboard receiving inputs and coordinating outputs. So long as all the inputs lead to the same location, (the global workspace to extend the metaphor), the soul should have access to all the mental contents realized by the brain at any time.

Fig. 1

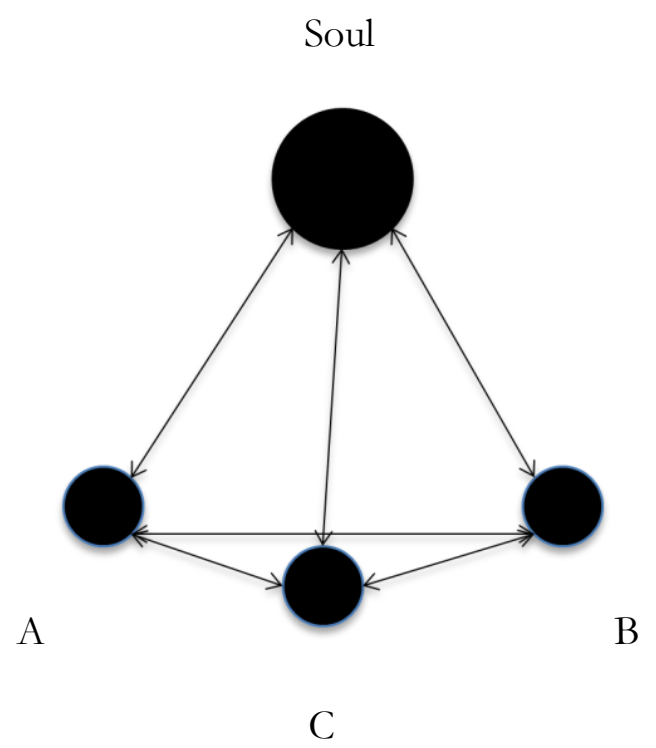

Figure 1 represents the global workspace view of the soul. Let A and B represent the physical realization in the brain upon which the mental states $\mathrm{A}^{*}$ and $\mathrm{B}^{*}$ depend, and let $\mathrm{C}$ represent the 
physical realization of the conjunction of $\mathrm{A}$ and $\mathrm{B}$. The soul has access to $\mathrm{A}^{*}, \mathrm{~B}^{*}$, and $\mathrm{C}^{*}$ in virtue of the fact that all three are causally connected to the same brain where they are realized (or subserved) or dependent upon three brain states A, B and C. Note that there are two levels of causation: on the "horizontal," or neurological level, A, B, and C interact with each other (and other brain states) within the properly functioning brain, while on the "vertical" level, the soul interacts with all three. The soul can think $A^{*}$ (a thought physically supported by A) iff the brain causally produces A; and the soul can think $\mathrm{B}^{*}$ iff the brain has causally produces $\mathrm{B}$; and the soul can think $\mathrm{C}^{*}$ iff it has causal access to $\mathrm{C}$ which is a result of the causal interactions of $\mathrm{A}$ and $\mathrm{B}$. And if $\mathrm{A}^{*}$ is to influence $\mathrm{B}^{*}$ or vice versa, and if the conjunction of $\mathrm{A}^{*}$ and $\mathrm{B}^{*}$ are be thought of together (as in $\mathrm{C}^{*}$ ), then the neurological state A must be causally related to the neurological state B. If such causal ties between $\mathrm{A}, \mathrm{B}$ and $\mathrm{C}$ are not in the brain, then there won't be causal relations between mental states $\mathrm{A}^{*}, \mathrm{~B}^{*}$ and $\mathrm{C}^{*}$ in the soul either. A will produce $\mathrm{A}^{*}$ in the soul, and B will produce B* in the same soul, but mental states $\mathrm{B}^{*}$ and $\mathrm{A}^{*}$ will not interact if physical states B and A don't. B* will not influence or be about $\mathrm{A}^{*}$, or vice versa, nor will thought $\mathrm{C}^{*}$ be about $\mathrm{A}^{*}$ and $\mathrm{B}^{*}$. Rather $\mathrm{A}^{*}$ and $\mathrm{B}^{*}$ will be as isolated from each other in the soul and A and B are in the brain. This isolation is only mysterious and a reason to doubt an immaterial soul if one neglects to attend to the neurological dependence of the soul's thought and thinks of the soul as point-like global workspace, i.e., all of its contents there together without barriers hindering co-consciousness.

Suppose A and B are located in separate hemispheres of the brain. In that case, whenever the brain is split, A and B are isolated in their respective hemispheres (for the sake of argument let's suppose that they are utterly isolated with no subcortical pathways to connect them). 
Fig. 2

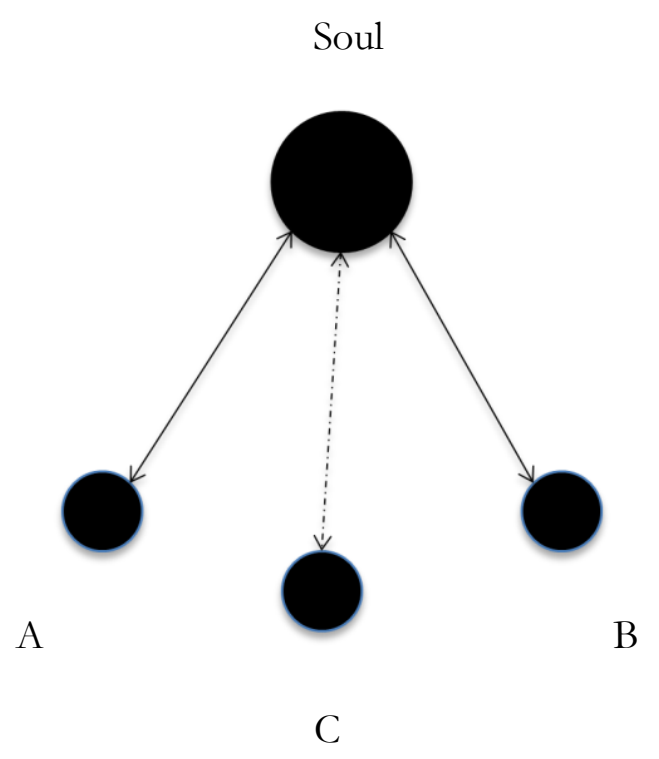

Figure 2 shows the result of the brain being split in such a way that the cognitive contents of brain states A and B are no longer horizontally accessible to each other, but the same soul has access to both mental states $\mathrm{A}^{*}$ and $\mathrm{B}^{*}$. It then appears that there are two distinct and simultaneous conscious events occurring in the soul, an $\mathrm{A}^{*}$ event and $\mathrm{B}^{*}$ event. It might seem that the soul should be able to generate $\mathrm{C}^{*}$ on it's own by filling in the relations between $\mathrm{A}$ and $\mathrm{B}$ and the missing $\mathrm{C}$. But it cannot. This gives rise to the mistaken impression that the soul theorist will have to implausibly posit there are now two souls where before there was one.

The soul is the subject of thought but it doesn't by itself determine which thoughts influence other thoughts. It is not some immaterial thing which regardless of the state of the brain can freely choose to reflect upon and rearrange its contents, weigh them against each other, draw inferences etc., anything in the soul being able to causally influence any other thoughts or be thought. It isn't that since thought $\mathrm{A}^{*}$ is in the partless soul, and since thought $\mathrm{B}^{*}$ is in the same partless soul, the immaterial thinker can reflect upon them both, compare them, adjust other thoughts in light of them etc. Rather the soul can think about $\mathrm{A}^{*}$ and $\mathrm{B}^{*}$, or think about $\mathrm{C}^{*}$ which takes into consideration $\mathrm{A}^{*}$ and $\mathrm{B}^{*}$, only because there are physical connections $\mathrm{A}, \mathrm{B}$ and $\mathrm{C}$ in the brain upon 
which the soul depends. ${ }^{9}$ On our account, the soul is more like an immaterial mirror than a global workspace. ${ }^{10}$ What goes on in the brain, has mental correlates that are immaterially reflected in the soul.

Readers might wonder how it could be the same soul if the soul is not individuated by the extent of the psychology accessible to it at any time? Well, one reason - but by no means the entire story of soul individuation - is that the soul is linked to that brain and will have thoughts subserved by that brain. When the brain's pathways are restored, the soul thinking the thoughts dependent upon that brain will be able to think those thoughts in relations to each other. The thoughts will be known in that special first person way, whatever it amounts to, that distinguishes your thoughts from another person's. When your brain is split there may be times that some of your thoughts have to infer some of your other thoughts in a manner somewhat akin to how you infer the thoughts of others. But the dependency upon the brain doesn't mean the soul will always have to draw such inferences. Being connected to one particular brain means that its contents are tied to connections within that brain. When the brain functions as it should, the soul will have a greater interaction between its thoughts than when the brain is damaged. But there is just one soul, a soul dependent upon the brain, but nevertheless, the thinker of the thoughts.

We don't think readers should protest that we haven't offered an account of how the soul and the body/brain are connected. The so-called "pairing problem" doesn't trouble those working within a theistic framework. Materialists are wrongly trying to tie the hands of the theists, not letting them work within their preferred framework in which God creates the soul. There isn't any pairing problem to explain if God has the creative power that he is standardly acknowledged to possess (Plantinga (2006), 132-134). Plantinga responds to Kim's pairing problem challenge by claiming that the linking is accomplished in a manner akin to God just saying "Let there be light" and there is light or God thinking "Let Adam exist" and therefore Adam comes to exist. So there is no new problem 
on top of any doubts readers may harbor about God's existence and powers. The theist believes that it is a necessary truth that what God wills is so. To ask why that is so is like asking why an equilateral triangle is also equiangular. We are content to let our theory succeed or fall with the status of God's existence and omnipotent nature.

\section{The Need for Souls and their Divine Origin}

We'll respond to a number of anticipated objections in this section. The first is why treat split brains differently from brains that are divided and transplanted? If we don't want to claim that two bodies are connected to the same soul in the transplant scenario, how can we avoid there being two souls each connected to a different hemisphere in the split brain case that involves just one body with a divided brain and no hemispheric removals and transplants?

If the brain is not just split but the parts removed and transplanted into different skulls, then we may have to tell a story about a new soul. But we may not. It could be that God keeps the soul paired with both hemispheres. But we prefer an account in which God creates one new soul when the brain's components are scattered in a way that will prevent the unity of agency. ${ }^{11}$ The emergentist account of the soul may claim that when a single brain is not involved with producing a soul but is split and each cerebral hemisphere transplanted, then there will be two souls. The emergentist claims the soul is where the brain is, perhaps something akin to an extended simple (Zimmerman (2010). If the parts of the brain are separated from each other, they won't together produce a single soul. When they are together, the cutting of the corpus callosum and the loss of a pathway results in not two souls but the one emergent soul being restricted in certain functions. The single brain produces a single soul, it is just that the soul can't do what it did before.

The emergent dualist view seems suspect when we consider non-overlapping parts of the brain that could each produce consciousness. If the split brain can give rise to thoughts cut off from each other, then transplanting those cerebral hemispheres into two disjoint bodies should do the 
same. Unlike the case of the split brain in one body, the two disjoint bodies would seem to be distinct agents. Moor and Korsgaard note that the split brain in a single body rarely produces any frustration of agency that one would expect if there really were two persons connected to a single body. But there would clearly be two distinct agents after the cerebral hemispheres were fissioned and transplanted. Yet prior to the fissioning and transplant, the hemispheres can't produce emergent souls or there will be two people where we want just one. So the presence of an adjacent cerebral hemisphere must somehow serve to prevent each hemisphere from giving rise to a soul. Yet this prevention must not prevent the soul from thinking the thoughts that are realized in the entire brain. This prevention puzzle of the emergent dualist provides some additional reason to think that God would instead provide the needed soul(s) for the transplanted hemispheres as well as the original soul of the earlier undivided brain.

Secular philosophers with dualist sympathies might opt for Unger's view of particular souls being disposed to be connected with bodies or brains. He thinks there is just one soul disposed to interact with certain arrangements of matter. But his account will suffer the same prevention problem that plagued Zimmerman's emergent dualism. It seems that parts of your brain could support thought if they appeared in different skulls of different bodies after fission and transplantation, so there would have to be souls disposed to interact with them. But why prior to fission would matter beyond the boundaries of each cerebral hemisphere block or extinguish the souls disposed to interact with them post fission?

Moreover, the Unger-inspired soul theorist, unlike the emergent dualist, has a time-indexed Ship of Theseus-like problem. Assume that all the matter that first composed your body gets gradually replaced and is later reassembled elsewhere. Supposedly there will be a soul disposed to the reassembled matter but now the propensities of the respective souls involve "memories" of sort, or rather are time-indexed in a way hard to fathom. The soul of the reassembled matter would 
somehow have waited its turn, not becoming involved with the matter earlier. The soul of the reassembled matter isn't your soul, which is still co-located with your replacement matter body. The soul theorist who accepts divine creation of souls will have a new soul created for the replacement body just as he posited in the split brain and transplant scenario.

However, secular materialists might object that there is no need for either Unger or ourselves to posit a soul with or without a divine creator. First, the Ship of Theseus-like problem for persons will just have the reassembled person thinking when its brain comes into existence appropriately organized. The original person has survived as the replacement person since organisms can replace all of their matter if it is done so gradually. Secondly, the neurological dependency of thought shows that souls can't think on their own so why posit them to think even dependent thoughts? Third, why can't the unity of agency provide the secular materialist with a single fully material agent and subject of thought in the split brain case? If such unity is providing soul theorists like the authors of this article with a single agent in the split brain case, why can't the materialist help himself to a simpler theory that eliminates the soul? Our response is that the single soul provides a single subject of thought whereas the materialist has no equivalent entity with which to individuate thinkers and agents. To see this we will turn to the reasoning that converted Unger from his materialism to dualism. And the same problem that inspired Unger's dualism leads Zimmerman to defend a suspect overdetermination of a single soul, an overdetermination that doesn't cohere well with the above prevention treatment required to deal with split brains.

So our question has become why posit a soul that depends upon the brain rather than just have the brain or the animal with the brain as the thinker? There are many reasons that have been given to deny materialism. The reductionist's seeming inability to explain experiential states in terms of the structural and functional explanatory accounts available to science is perhaps the most famous. But we are especially fond of one in particular that motivates Zimmerman (2010) and 
Unger (2006) that ties into the threat of extra thinkers with split brains and transplanted hemispheres. This is what Unger has labeled The Problem of the Thinking Many which is a variation on his earlier celebrated Problem of the Many. Unger's Problem of the Many arises when it is assumed that entities have a determinate boundary, although this border occurs in a grey area where the object's component stuff falls off, i.e., becomes scarcer. For instance, simplifying a bit, a cloud consists mostly of water droplets grouped together. At the cloud's centre, the droplets are tightly bunched together. As we move away from the clear centre of the cloud, the water droplets will gradually lessen. It is the thinning of the droplets on the outskirts of the cloud that pose a problem: How do we determine the exact border of the cloud in this grey area? And Unger warns a cloud must have a border or our entire world would just consist of cloud-like stuff.

The dilemma is that any line drawn in a grey area around a mass of water droplets seems no better suited to being the boundary of a typical cloud than an alternative line that encompasses, for instance, all but one of the same droplets. And any large number of these same droplets can be joined with still other droplets that were outside but adjacent to the first boundary. And if the first grouping qualifies as a typical cloud, then, surely, so do the groupings that are only slightly different. Thus The Problem of the Many is that there will be a great number of paradigmatic clouds each with perhaps only one droplet more or less than the next cloud that it bounds or is embedded within.

Although Unger first illustrated The Problem of the Many with clouds, a version with brains or animals can be given as well. ${ }^{12}$ Given the vagueness of which simples are those of our outermost boundary, there would be many equally good candidates for us. If we are composed of one set of particles rather than another set including say one more or one less atom, the other would also be a perfectly fine candidate for being a thinking creature like ourselves. So overlapping us, completely or partially, would be many entities using our neurological equipment to think (Unger (2006)). The same overlap appearing at the organism's boundaries will also appear at the brain's boundary bringing 
countless equally good candidates to be the brain. Unaided materialism cannot offer us a palliative against the possibility of these additional candidate thinkers. ${ }^{13}$ But the soul theory, especially as we have presented it, can do so. It tells us that brains alone are not sufficient for the production of thought. Only with the soul, which provides unity and subjectivity to its activities (or events) can the brain achieve thought.

Unger's solution to The Problem of the Thinking Many is to have a single soul disposed to pair up with any number of overlapping bodies. The emergentist solution is to have just one soul emerging from all the brains configured a certain way. The emergent dualism account is problematic because all the equally good overlapping physical candidates should be able to produce different souls. But Zimmerman argues that they overdetermine the same soul. This view strikes us as dubious.

Moreover, materialists may think they can help themselves to Zimmerman-style overdetermination. If it works for soul, why couldn't it work for a materialistic single candidate thinker overdetermined by many overlapping material objects? They might object that whatever relation is posited to connect the many bodies to one soul could just as well connect them to one (soulless) material thinker. ${ }^{14}$ But we think it is ad hoc for either the soul theorist or the materialist to appeal to overdetermination to obtain a single thinker. Still, the situation is worse for the materialist. We don't think the materialist can avoid too many thinkers by appealing to some relation between all the candidate brains and bodies and a single material thinker. For example, if all the material candidates overdetermine or constitute the same material person, why don't all the overdetermining or constituting entities also have the capacity to think? There aren't physically significant differences between them and the overdetermined or constituted thinker. Moreover, we can imagine many of the larger overlapping entities losing parts and becoming spatially coincident with the other entities that overdetermine or constitute a thinker consisting of the very same physical parts. But why can't 
the former think? This is the standard grounding objection to spatial coincidence, constitution and extensive overlap. Since materialists maintain it is things composed of matter that think, then it is hard to see why comparably arranged composites of matter should not be able to think. It is easier to defend a position that denies any material beings can think than try to insist that only one of the many overlapping or spatially coincident material beings can think. So it isn't as philosophically contentious to claim that many material things that overlap connect to an immaterial soul that thinks than it is to claim that all but one of these physically indistinguishable or virtually indistinguishable material things can't think. The relationship between thinkers and non-thinkers is far more mysterious on materialist grounds than it is in the dualist framework. Linking all the overlapping bodies to one thinking soul is very different than linking them to one thinking material thing. A thinking soul is a very different kind of entity than a material thinker.

\section{Conclusion}

We have argued that the split-brain objection to soul theory, as espoused by thinkers like McMahon and Parfit (and many others), fails because it relies on a pair of mistakes: first, it fails to take seriously the dependence of the soul's thought on its bodily organ of thought (the brain). And second, it treats the soul, on account of its simplicity, as a sort of global workspace in which all the thoughts of the soul are necessarily unified and accessible regardless of the state of the brain. We've shown that once these mistakes are identified and assiduously avoided, a soul-theory can be stated which makes sense of the apparently contradictory data of the split-brain phenomenon. After motivating the need for a soul due to the challenge of Unger's Problem of the Thinking Many, we offered theistic story about the soul's origins to handle an extension of the split brain phenomenon. We claimed the theistic account does a better job than its immaterial rivals in explaining why there is just one soul in the ordinary case and two when the cerebrum is fissioned and the cerebral hemispheres transplanted..$^{15}$ 


\section{References}

CHALMERS, DAVID. (1996) The Conscious Mind. (Oxford: Oxford University Press.)

HASKER, WILLIAM (2001) The Emergent Self. (Ithaca: Cornell University Press.)

KORSGAARD, CHRISTINE (1989) 'Personal Identity and the Unity of Agency: A Response to Parfit.' Philosophy and Public Affairs 18, 101-132.

MCMAHAN, JEFF (2002) The Ethics of Killing: Problems at The Margins of Life. (Oxford University Press.)

MOOR, JAMES (1982) 'Split Brains and Atomic Persons', Philosophy of Science 49, 91-106.

PARFIT, DEREK (1984) Reasons and Persons. (Oxford: Oxford University Press).

PLANTINGA, ALVIN (2006) 'Materialism And Christian Belief,' In Dean Zimmerman and Peter van Inwagen (eds) Persons Human and Divine. (Oxford: Oxford University Press).

SWINBURNE, RICHARD and SHOEMAKER, SYDNEY (1984) Personal Identity (London: Basil Blackwell).

ROSS, JAMES (2001) 'Together with the Body I Love’ Proceedings of the American Catholic Philosophical Association. 75, Person, Soul and Immortality.

TAYLOR, ADAM P. (2013) 'The Frustrating Problem for Four-Dimensionalism” Philosophical Studies, 165, 1097-1115.

TAYLOR ADAM P. and HERSHENOV, DAVID B. 'Dualism, Panpsychism and the Moral Status of the Brainless.' Unpublished.

VAN DYKE, CHRISTINA (forthcoming) 'I See Dead People: Disembodied Souls and Aquinas’s 'Two Person' Problem.' Oxford Studies in Medieval Philosophy. Forthcoming VAN INWAGEN, PETER (1993) Material Beings. (Ithaca: Cornell University Press).

UNGER PETER (1980) 'The Problem of the Many,' Midwest Studies in Philosophy, 5 411-468. (2006) All The Power In the World. (New York: Oxford University Press). 
(2004) 'The Mental Problems of the Many' in Dean Zimmerman (ed.) Oxford Studies in

Metaphysics I, (Oxford: Oxford University Press), 195-221.

1980. The Problem of the Many. Midwest Studies in Philosophy 5, 411-468.

ZIMMERMAN, DEAN (2010) 'From Property Dualism to Substance Dualism'. The Proceedings of the Aristotelian Society LXXXIV. 119-150.

${ }^{1}$ See (McMahan (2002), 20-22) and (Parfit (1984), 247).

${ }^{2}$ Theists typically maintain that the religious promise of posthumous existence requires that materialists are wrong about the nature of human persons. Many theists also maintain that their belief that they are made in God's image as free agents and knowers isn't compatible with a wholly material composition.

${ }^{3}$ A referee claimed that our appeal to a divinely created soul is ad hoc. But it isn't as if we put forth a theory and made predictions that didn't come true and then introduced epicycles or left some phenomena unexplained and then relied upon God to fill in the gaps. We are drawing upon traditional soul theories that posit a divine creator and not a soul that emerges from nature. Then we use cerebral division and transplant scenarios to show that the newfangled theories of emergentist and disposed souls couldn't account for such phenomena. So the traditional approach doesn't need to be changed or modified in an ad hoc manner, we merely are showing its strength in dealing with new problems that the tradition didn't consider and the newfangled soul theories can't resolve. ${ }^{4}$ Swinburne uses the analogy of a light bulb and the socket, maybe it can work with a different socket, but some is needed. See (Swinburne (1984), 34). Readers shouldn't think the soul's dependency on the brain makes for a mindless disembodied posthumous existence which would be undesirable and at odds with typical views of the afterlife. There are a few responses that can be made why this isn't so. In the Thomistic tradition, God replaces the missing brain provided 
ingredients of cognition (phantasms, i.e., images in the brain) that enabled the living hylomorphic soul/body composite to think with "intelligible species" when the soul of the person is disembodied. The deceased's soul comes to think in a manner akin to that of bodiless angels. Emergent dualists (Hasker (2001), 232-235) tell a somewhat similar story of God sustaining the soul when the body is gone. Other possibilities involve immediate Resurrection (van Dyke, forthcoming) and transitional bodies between death and resurrection (Ross (2001).

${ }^{5}$ If the reader has difficulty understanding what Unger means by a "non-spatial spacelike" dimension, we sympathize. We believe that there is an alternative available to the dualist. See our unpublished "Dualism, Panpsychism and the Moral Status of the Brainless". Much of the detail of this highly speculative soul theory of Unger's is intended to get us around what Unger calls the "The Problem of the Thinking Many." We discuss this problem in the final pages of the present paper. ${ }^{6}$ Unger frequently writes of propensities where others write of dispositions.

${ }^{7}$ Someone, not us, might assume that the soul has a spatial analogue of parts. That might open up avenues to the dualist to explain the split brain phenomena. We suspect that they just push back questions of the soul's individuation. We should mention that the traditional reason not to think of the soul as having parts is then it might be divisible and destructible. If the soul is simple it can't be destroyed by corruption via division into its parts but only by God's annihilation. We are construing the relationship of thoughts to the soul not as parts to a whole, but modes or states of a substance. The same immaterial thing can have different states just as the same material thing can have distinct properties or participate in distinct events at the same time. For example, a kiss could be intense, passionate, sloppy, enjoyable and romantic and such distinct properties or events would have different causal effects without being spatially distinct. Moreover, the dependency of the soul and its states on different parts of the split brain make it more plausible that the resulting immaterial states are distinct. 
${ }^{8}$ We adapt the notion of a global workspace from Chalmers who took it from Bernard Baars. According to this understanding, "consciousness is a kind of global workspace in a distributed system of intelligent informational processors. When processors gain access to the global workspace, they broadcast a message to the entire system, as if they had written it on the blackboard. The contents of the global workspace are the contents of consciousness.” (Chalmers (1996), 112).

${ }^{9}$ This should not be thought to be at odds with free will. However the materialist libertarians or compatibilists account for free will, the soul theorist can help herself to their respective finding. And if the determined agent can be free because she values and endorses or identifies with a secondorder intention but couldn't have acted otherwise, the soul theorist can accept the neurological mechanics of that compatibilist account. If there is indeterminacy preceding the choice between two options that the agent has some reason to pursue, the soul theorist can make use of that undetermined brain state to have libertarian free choice. It might seem that if libertarian free will is possible because of the soul, then the soul has some independence from the body. But we're not committed to this independence. And if we were to endorse it, it would be a restricted independence that wouldn't affect our thesis. Such a (restricted) libertarian "active" soul could choose between A* and $\mathrm{B}^{*}$ after comparing them, the choice not determined by the physical world. But $\mathrm{A}^{*}$ and $\mathrm{B}^{*}$ could only be compared if they were physically instantiated and causally related to each other. The soul would be free to choose but it won't follow that the soul could consider the contents generated by the two hemispheres of a split brain. The purpose of the immaterial soul is to provide unity and a single subject of thought, whose thoughts depend upon the brain's operations.

${ }^{10}$ Don't read our mirror metaphor as though it implied a robust isomorphism. 
${ }^{11} \mathrm{~A}$ referee protested that it is arbitrary that the soul goes with one cerebral hemisphere and not the other. But it isn't a problematic arbitrariness, rather just a coin toss that doesn't matter ontologically. It is God's choice between two equally good options. It is perhaps preferable that no one go out of existence with fission but it doesn't need to be explained why the original person is chosen by God to continue with one cerebral hemisphere rather than the other. We are not asking for why one half of the brain resulting from fission would naturally commandeer the soul and not the other that is qualitatively identical. Then there might be something needing an explanation. But if they are perfect duplicates then there is no need for an explanation why God chooses one than the other. It is like us considering which of two qualitatively identical snacks to eat.

${ }^{12}$ Unger mentions persons in his original (1980) article in the Midwest Studies in Philosophy

${ }^{13}$ Someone might follow Lewis and insist that we don't count by identity but by overlap. But revisionary practices of counting don't help get rid of the counter-intuitiveness of there being nonidentical thinkers. Counting two non-identical thinkers as one because they overlap doesn't take away from the bizarre nature of there being distinct overlapping thinkers.

${ }^{14}$ A referee suggested this.

${ }^{15}$ Acknowledgements: We would like to thank two anonymous referees, Thomas Flint, Robin Le Poidevin, and especially Joel Potter. 